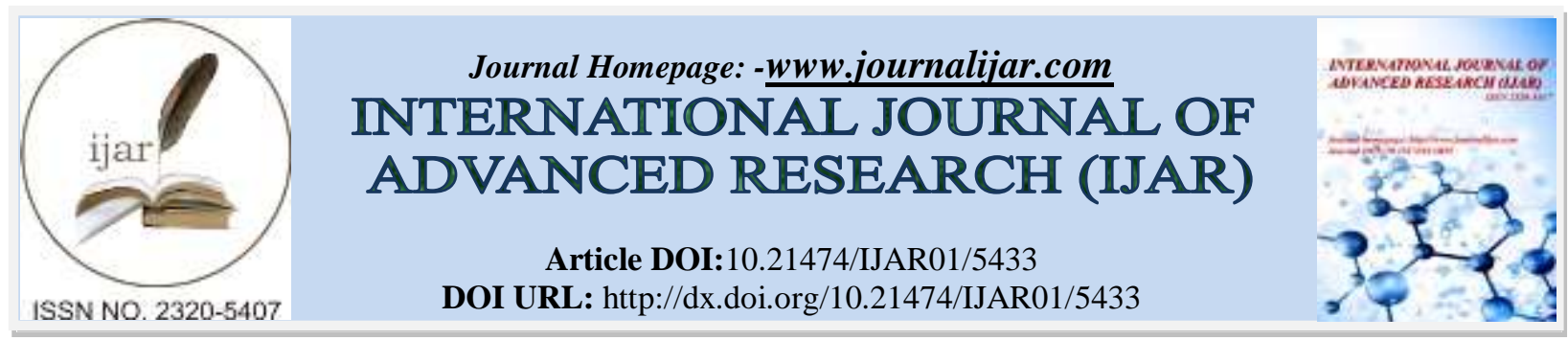

RESEARCH ARTICLE

\title{
Prediction of Stature from Arm-span Measurements in Undergraduate Students of College of Medical Science and Teaching Hospital, Chitwan.
}

Dr. Ruku Pandit.

Lecturer, Department of Anatomy, College of Medical Sciences and Teaching Hospital, Chitwan, Nepal.

\section{Manuscript Info}

Manuscript History

Received: 15 July 2017

Final Accepted: 17 August 2017

Published: September 2017

Key words:-

Observed Height; Calculated Height; Arm-Span.

\section{Abstract}

Introduction: Identification of an individual is the necessity during mass disasters and becomes troublesome when decomposed, mutilated or only fragmentary remains of body part are discovered. In such circumstance, stature forms a basis for identification of obscured deceased bodies. Various anthropometric measurements of different body parts (head, trunk, upper and lower limb) have been used to estimate the stature accurately, among which, arm-span has been considered as one of the most valid parameter.

Aim: To formulate the regression equations to estimate the stature from arm-span.

Materials and Methods: The cross-sectional analytical study was conducted in 197 students consisting of 100 females and 97 males, in College of Medical Science, Bharatpur, Nepal. Height and arm-span of each student were measured with Stadiometer and calibrated steel tape respectively. The data was analysed using SPSS version 16.0.

Results: The mean values of arm-span and height were statistically higher in males than in females $(\mathrm{p}<0.05)$. The arm-span and height showed strong positive correlation with each other in both sexes and the correlation was significant $(p<0.05)$. The coefficients of determination were 0.656 and 0.712 in males and females respectively, indicating that predicting stature, when taking into account arm-span is higher in both sexes. The calculated height (computed using regression equations) revealed no significant difference from the observed height in both male and female students ( $\mathrm{p}>0.05)$.

Conclusion: This study provides regression equations to estimate stature from the arm-span measurements, as arm-span is a reliable predictor of stature.

Copy Right, IJAR, 2017,. All rights reserved.

\section{Introduction:-}

Stature is defined as natural height of a person in erect position. Identification of an individual is the necessity during mass disasters and is upsetting when decomposed, mutilated or only fragmentary remains of body part are discovered. ${ }^{1}$ In such circumstance, stature of an individual forms a basis for identification of obscured deceased bodies. ${ }^{2}$

Corresponding Author:-Dr. Ruku Pandit.

Address:-Lecturer, Department of Anatomy, College of Medical Sciences and Teaching Hospital, Chitwan, Nepal. 
The body height is a paradigmatic parameter in evaluating the children's development and growth, $\underline{-}$ calorie demand of the body and accessing the nutritional status. ${ }^{4}$ Calculation of an accurate height of an individual with deformities of the vertebral column ((lordosis, kyphosis and scoliosis) or those with various disfigurements of extremities (excision of lower limb, fracture, etc) is troublesome. In such situation, an estimated body height can be figured out using various anthropometric determinants, as the proportionate relationship between the height of an individual and measurements of different segments of the body (head, trunk and extremities) has been authenticated by various surveys. $\underline{5} \underline{\underline{6}}$

Stature correlates well with arm-span,,-7 and can be used to compute the height particularly when the patient is bedridden or suffering from debilitating disease and is unable to stand upright. Although many literatures has been cited on estimation of stature from arm-span length, but, limited data is available on Nepalese community. Hence, we conducted this study to generate the regression equation to calculate stature from the arm-span which will be immensely useful to the forensic pathologist in the identification of a living or deceased individual and physical anthropologists for determination of stature from the fragmentary vestiges of upper limb.

\section{Materials and methods:-}

We conducted a cross sectional analytical study in Department of Anatomy, College of Medical Sciences and Teaching Hospital, Bharatpur, Nepal. It is KU affiliated medical school which runs undergraduate courses in various discipline (MBBS, BDS and BSc Nursing) apart from postgraduate courses. After obtaining clearance from institutional ethical committee, we collected data from 197 undergraduate students from March to May 2017. Students with skeletal deformities, physical disabilities, past history of skeletal injuries or diseases affecting bones and joints and those on any form of hormonal medications were excluded from the study. All the subjects were briefed about the purpose of study and informed and written consent was obtained.

The parameters measured were:

\section{Arm-span:-}

It was measured with a calibrated steel tape from the tip of the middle finger of one arm to the tip middle finger of other arm with arms outstretched at right angles to the body, in bare feet on a level concrete floor with upper backs, buttocks and heels against the wall.

\section{Height/ stature:-}

It was determined by Stadiometer. It is measured as a distance from vertex (highest point on the head) to heel while standing in Anatomical position with bare foot on flat platform of Stadiometer. Both the measurements were taken to the nearest $0.1 \mathrm{~cm}$

All the measurements were taken by principle author in order to minimize bias and error of identification of the landmarks involved in measurement. The measurements were taken twice, and an average of the two readings was calculated. Data obtained were first entered in Epidata 20.1 and analysed with Statistical Package for Social Sciences (SPSS) version 16.0. Kolmogorov-Smirnov test (Normality of distribution) showed normal distribution for both anthropometric variables (height and arm-span). Means and standard deviations (SD) of stature and arm-span were calculated. An Independent t-Test was performed to examine gender difference in measurements of arm-span and height. The relationship of height with arm-span was determined using simple (Pearson) correlation coefficients. Then a linear regression analysis was performed to formulate an equation which predicts body height from armspan. Estimated height of students was then calculated adopting the derived regression equations and the former was compared with the observed height using Paired $t$ test. A p-value $<0.05$ was considered significant.

\section{Results:-}

Of the total 197 undergraduate students, 100 were females (50.76\%) and 97 were males (49.24\%).The students were categorized into three groups on the basis of height and arm-span (group 1- height=arm-span, group 2- height>armspan, group 3- height<arm-span). Majority of the students $(171,86.80 \%)$ had height less than arm-span, out of which, 89 were males and 82 were females; followed by 25 students who showed less arm-span in comparison to the stature. Only one male student had height equivalent to arm-span.

Table 1:- Distribution of study group on the basis of height and arm-span.

\begin{tabular}{|l|l|l}
\hline Group & Male (97) & Female (100) \\
\hline
\end{tabular}




\begin{tabular}{|l|l|l|l|}
\hline Group 1 & $1(1.03 \%)$ & $0(00 \%)$ & $1(0.51 \%)$ \\
\hline Group 2 & $7(7.22 \%)$ & $18(18 \%)$ & $25(12.69 \%)$ \\
\hline Group 3 & $89(91.75 \%)$ & $82(82 \%)$ & $171(86.80 \%)$ \\
\hline Total & $97(100 \%)$ & $100(100 \%)$ & $197(100 \%)$ \\
\hline
\end{tabular}

Mean and standard deviation of observed height for males and females were $170.53 \pm 5.65 \mathrm{~cm}$ and $157.29 \pm 6.21 \mathrm{~cm}$ respectively. On the other hand, the mean arm-span of the males was $177.06 \mathrm{~cm}$ with a standard deviation of 7.78 $\mathrm{cm}$; while, that of females was $160.28 \mathrm{~cm}$ with a standard deviation of $7.37 \mathrm{~cm}$. An Independent t-Test confirmed that the differences of observed height and arm-span between males and females were statistically significant $(\mathrm{p}<0.05)$, mean values of arm-span and height being greater in males than in females.

Table 2:- Stature and arm-span in males and females.

\begin{tabular}{|l|l|l|l|l|l|}
\hline \multirow{2}{*}{ Measurements } & \multicolumn{2}{|l|}{ Male (97) } & \multicolumn{2}{l|}{ Female (100) } & P value \\
\cline { 2 - 6 } & Range & Mean \pm SD & Range & Mean \pm SD & \\
\hline Observed height & $157.60-185.20$ & $170.53 \pm 5.65$ & $141.70-175.20$ & $157.29 \pm 6.21$ & $<0.05$ \\
\hline Arm-span & $158.00-199.30$ & $177.06 \pm 7.78$ & $146.20-183.50$ & $160.28 \pm 7.37$ & $<0.05$ \\
\hline
\end{tabular}

A simple linear regression was calculated to predict height (calculated height) based on arm-span measurements as shown in Table 3. The significant regression equations were found with $\mathrm{R}^{2}$ (coefficient of determination) of 0.656 for males and 0.712 for males. Their relationship was plotted in scatter diagrams as illustrated in Figures 1 and 2.

Table 3:- Regressing equations for the estimation of stature from arm-span in males and females.

\begin{tabular}{|l|l|l|l|l|}
\hline Gender & $\begin{array}{l}\text { Correlation } \\
\text { coefficient }(\mathrm{r})\end{array}$ & $\begin{array}{l}\mathrm{r}^{2} \quad \text { (coefficient of } \\
\text { determination) }\end{array}$ & Regression equation & P values \\
\hline Male & 0.81 & 0.656 & $66.44+(0.59 * \mathrm{AS})$ & $<0.05$ \\
\hline Female & 0.84 & 0.712 & $43.40+(0.71 * \mathrm{AS})$ & $<0.05$ \\
\hline
\end{tabular}

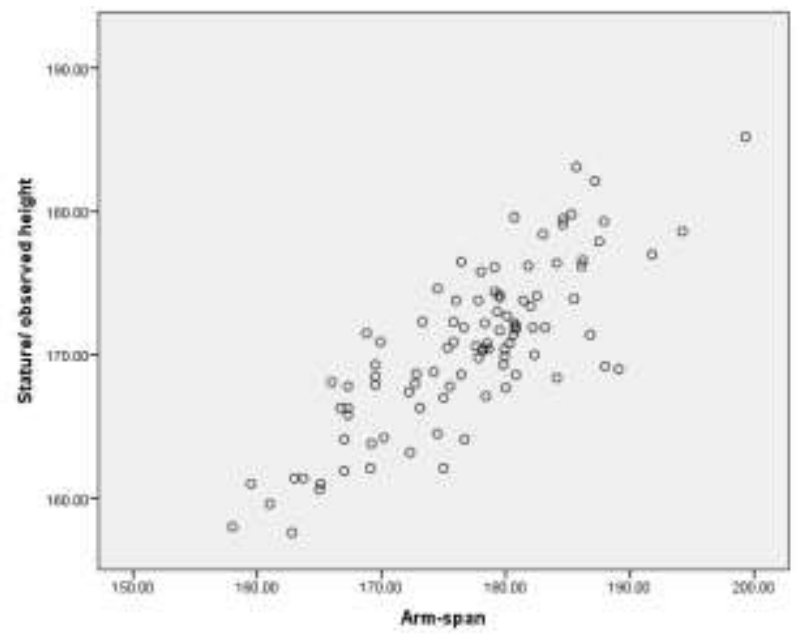

Figure 1:- Scatter diagram showing relation between stature and arm-span in males.

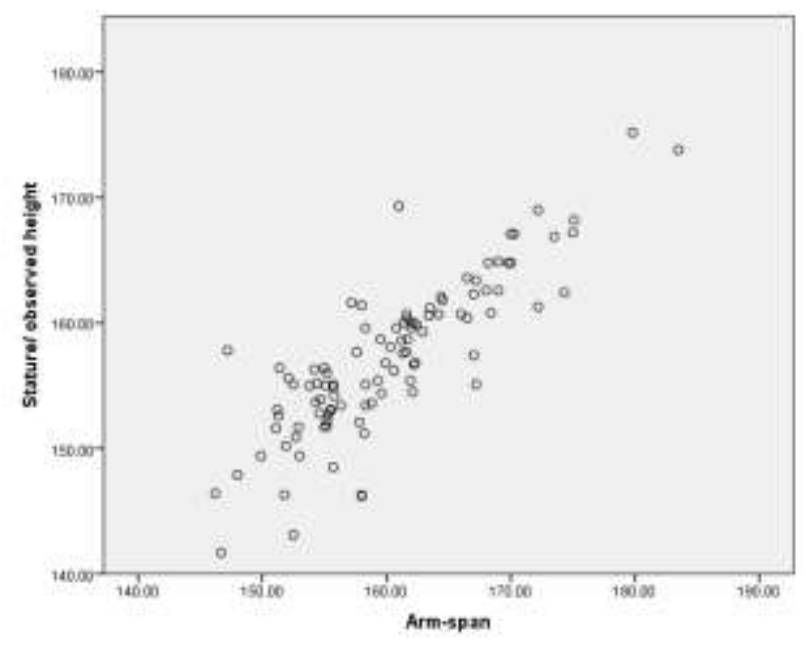

Figure 2:- Scatter diagram showing relation between stature and arm-span in females.

By using these regression equations, height of each student was calculated. The calculated height of the males ranged between $159.66 \mathrm{~cm}$ to $184.03 \mathrm{~cm}$ with mean and standard deviation of $170.90 \pm 4.59 \mathrm{~cm}$; while, that of the females fluctuated between $147.20 \mathrm{~cm}$ to $173.69 \mathrm{~cm}$ with mean and standard deviation of $157.20 \pm 5.23 \mathrm{~cm}$.

Table 4:- Calculated height using regression equations in males and females.

\begin{tabular}{|l|l|l|l|}
\hline Gender & Measurements & Range & Mean \pm SD \\
\hline Males & Calculated height & $159.66-184.03$ & $170.90 \pm 4.59$ \\
\hline Females & Calculated height & $147.20-173.69$ & $157.20 \pm 5.23$ \\
\hline
\end{tabular}


The calculated height was compared with the observed height of the students using Paired t test. The test revealed that there was no significant difference between observed and calculated height of both male and female students, $\mathrm{p}>0.05$.

Table 5:- Comparison between the observed and calculated height of males and females.

\begin{tabular}{|l|l|l|l|l|}
\hline \multirow{2}{*}{ Gender } & Calculated height & Observed height & t & P value \\
\cline { 2 - 5 } & Mean \pm SD & Mean \pm SD & & \\
\hline Male & $170.90 \pm 4.59$ & $170.53 \pm 5.65$ & -0.009 & 0.274 \\
\hline Females & $157.20 \pm 5.23$ & $157.29 \pm 6.21$ & 0.281 & 0.779 \\
\hline
\end{tabular}

\section{Discussion:-}

Several anthropometric measurements of body parts had been adopted to estimate the body height of an individual over the past centuries with variable degree of success. Jitendar et al in a study on 103 subjects (52 male and 51 female) in age group of 21-32 years in Hariyana state, reported significant correlation between height and foot length $(\mathrm{r}=0.969) .{ }^{-}$Pawar et all used hand length to estimate the height $;{ }^{9}$ while Mitchell calculated the stature from arm length. $\stackrel{10}{ }$ Among all, prediction of stature from the arm-span was found to be the most reliable..$^{7}$

Alam et al conducted a study on 124 MBBS students ( 85 males and 39 females) in Hind Institute of Medical Science in Sitapur and noted that majority of males (57) had arm-span greater than height whereas, most of the females (27) had height greater than arms span and 15 (11 males and 4 females) of them had height and arm-span identical. ${ }^{7}$ In a similar study by Kavyashree et al, the measurement of arm-span surpassed that of height in different ethnic groups and in both sexes. 11 The ration of height and arm-span was 0.98-0.99, denoting height to be marginally less than arm-span in both males and females. ${ }^{4}$ In the current study, majority of both sexes ( 89 males and 82 females) had height less than arm-span and only one male student had height equivalent to arm-span [Table 1].

In a study by Alam, the mean and standard deviation of stature and arm-span for males were $171.34 \pm 9.71 \mathrm{~cm}$ and $174.27 \pm 8.63 \mathrm{~cm}$ respectively and that for females were $159.41 \pm 6.33 \mathrm{~cm}$ and $156.47 \pm 7.85 \mathrm{~cm}$ respectively. The mean values of arm-span and stature in males were statistically higher than that in females $(\mathrm{P}<0.001) .{ }^{7}$ Similar findings were observed in the current study, in which, the mean and standard deviation of stature and arm-span for males were $170.53 \pm 5.65$ and $177.06 \pm 7.78$ respectively and that for females were $157.29 \pm 6.21 \mathrm{~cm}$ and $160.28 \pm 7.37 \mathrm{~cm}$ respectively [Table 2], with males having greater values of both arm-span and height than females $(\mathrm{p}<0.05)$.

Steele and Chenier conducted a study on black and white women in the age-group 35-89 and reported a significant correlation between height and arm-span of both black $(r=0.852, p<0.05)$ and white $(r=0.903, p<0.05)$ women. $\frac{12}{\text { In a }}$ similar study by Alam et al, the stature was found to correlate positively with arm-span (males, r=0.689; females, $r=0.783){ }^{7}$ Likewise, Sah et al, in a study on 400 subjects (225 males and 175 females) of Birgunj district of Nepal, observed that a significant positive correlation exist between the height and arm-span of both sexes, with correlations coefficient of 0.682 in males and 0.507 females. $\frac{13}{}$ All these findings support the results of the current study in which, a significant correlation was noted between stature and arm-span in both the sexes; correlation coefficient being 0.81 and 084 in males and females respectively [Table 3; Figure 1, 2].

The arm-span is a reliable predicament of the stature of an individual. According to Mohanty et al, the coefficient of determination for regression equations (to estimate height from arm-span) in South Indian women was 66.6\% and $31.5 \%$ for standing and sitting height respectively ${ }^{1}$ while, it was $47.5 \%$ for male and $61 \%$ for females in a study carried out by Alam et al. ${ }^{7}$ In our study, predicting stature, when taking into account arm-span was $65.6 \%$ in males and $71.2 \%$ in females, which were much higher than those in others study [Table 3].

Furthermore, we calculated the height of an individual from the arm-span using regression equations and observed that the calculated height and the observed height showed no significant difference in both males and females, $\mathrm{p}>0.05$ [Table 5] which is similar to the findings of Alam et al. ${ }^{7}$

\section{Limitation:-}

The present study was undertaken in students of MBBS first and second years with relatively small sample size (comprising of 197 students). Other attributes such as race, ethnicity and age were not considered. Hence, result of the study may not be generalized to overall Nepalese population. Nevertheless, the regression equations, we devised, 
may be considered as a reliable alternative to estimate the stature (from arm-span) of an individual in an emergency, particularly when the patient is bedridden or suffering from debilitating disease and unable to stand upright.

\section{Conclusion:-}

Arm-span correlated well with the stature in our study, and, can be used as a reliable predictor of height of an individual. These regression equations may be immensely useful to the forensic pathologist when stature becomes a critical factor in identification of a living or deceased and also to the physical anthropologists when stature has to be determined from the fragmentary vestiges of upper limb.

\section{References:-}

1. Mohanty S, Babu SS, Nair NS. The use of arm span as a predictor of height: A study of South Indian women. Journal of Orthopaedic Surgery. 2001;9(1):19-23

2. Vij K. Textbook of Forensic Medicine and Toxicology. 5 ed. New Delhi: Elseiver; 2011. p. 37.

3. Golshan M, Crapo RO, Amra B, Jensen RL, Golshan R. Arm span as an independent predictor of pulmonary function parameters: validation and reference values. Respirology. 2007;12(3):361-6

4. Datta B, Sudip. Arm span as a proxy measure for height and estimation of nutritional status: A study among Dhimals of Darjeeling in West Bengal India. Annals of human biology. 2011;38(6):728-35

5. Modibbo M, Ojo S, Magaji M, Esomonu U. Estimation of stature in Hausa Neonates of Kano, Nigeria using anthropometric measurements of weight, foot length, and foot breadth. BEST Journal. 2012;9:67-73

6. Anas I, Esomonu U, Zagga A. Prediction of stature of Hausa ethnic group using hand length and breath. Journal of medicine in the tropics. 2010;12(1)

7. Alam MT, Singh S, Rai R, Shaheen S. Correlation between Stature and Arm Span: A Prospective Regional Study in Eastern Uttar Pradesh. Annals of International medical and Dental Research. 2016.10.21276/aimdr.2016.2.3.15

8. Jakhar JK, Pal V, Paliwal P. Estimation of height from measurements of foot length in Haryana Region. 2010

9. Pawar PK, Dadhich A. Study of correlation between human height and hand length in residents of Mumbai. Int J Biol Med Res. 2012;3(3):2072-75

10. Mitchell C, Lipschitz DA. Arm length measurement as an alternative to height in nutritional assessment of the elderly. Journal of parenteral and enteral nutrition. 1982;6(3):226-9

11. Kavyashree A N, Bindurani M K, Asha K K, Subhash L P. Arm Span as Predictor of Stature among Indian Population. RJPBCS. 2016;6(3):802

12. Steele M, Chenier T. Arm-span, height, and age in black and white women. Annals of human biology. 1990;17(6):533-41

13. Sah R, Kumar A, Bhaskar R. Body height and its estimation utilizing arm span measurements in population of Birgunj Area of Nepal: an anthropometric study. Journal of College of Medical Sciences-Nepal. 2014;9(4):9-14 